\title{
Cosmopolíticas e cosmopoéticas do contato
}

\author{
Marcelo R. S. Ribeiro*
}

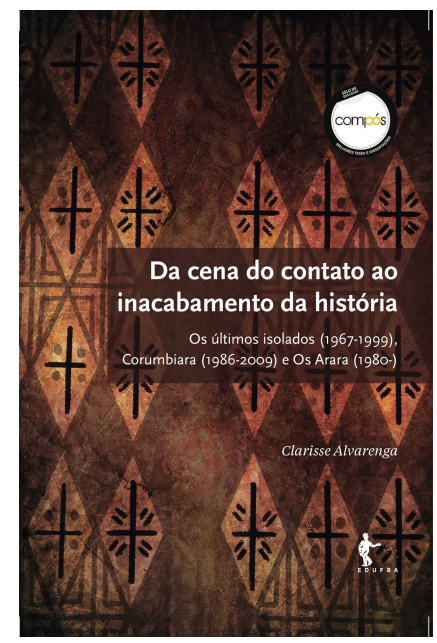

Alvarenga, Clarisse (2017). Da cena do contato ao inacabamento da história: Os últimos isolados (1967-1999), Corumbiara (1986-2009) e Os Arara (1980-). Salvador: EDUFBA. ISBN: 9788523215934.

Pensar a relação entre culturas - em sua multiplicidade de modalidades: o contato, o encontro, o choque, a diferença, o convívio etc. - é uma das tarefas fundamentais das ciências humanas e sociais. Para responder ao desafio dessa tarefa, que será sempre política, é preciso articular uma compreensão histórica de cada contexto de relação, que identifique atores envolvidos, datando as etapas e as fases das relações que estabelecem entre si e contextualizando os processos que se desdobram, de modo variável, em meio a essas relações. Ao mesmo tempo, qualquer relação entre culturas não pode se tornar compreensível sem o reconhecimento do que se poderia denominar sua experiência, ou dimensão experiencial, que deve ser interrogada naquilo que ela tem de irredutível a fixações de identidade cultural, a marcações de cronologia histórica e a delimitações de contextos. É preciso suplementar a compreensão histórica dos processos de relação entre culturas, em geral, com uma interrogação antropológica e cosmológica da constelação de sentidos que toda relação mobiliza

* Universidade Federal da Bahia - UFBA, Faculdade de Comunicação, Departamento de Comunicação. 40170-115, Salvador, Bahia, Brasil. E-mail: marcelorsr@ufba.br 
e desloca - e talvez seja preciso dizer, inicialmente sem maiores explicações, de modo talvez impertinente em relação ao livro que (re)leio ao escrever estas linhas: uma interrogação cosmopolítica e cosmopoética do contato e das derivas de sentidos que sua experiência inaugura, a cada vez em que é realizada e sempre que venha a ser retomada, na memória e na imaginação.

Quando Clarisse Alvarenga se dedica a pensar a cena do contato que se estabelece entre cineastas brancos e alteridade indígena, especificamente em filmes que abordam situações de primeiro contato, sua perspectiva articula uma compreensão histórica e antropológica da relação intercultural que, em contextos e de modos diferentes, atualiza a experiência do contato, cuja genealogia remonta ao encontro e ao choque inaugurais do colonialismo moderno. $\mathrm{Se}$ "tanto colonizadores quanto indígenas produzem narrativas sobre o contato que passou a vinculá-los uns aos outros" (p. 17), Clarisse apresenta, desde o início, como um de seus pressupostos, uma compreensão aberta dessa produtividade: "o contato é elaborado e reelaborado sistematicamente, ao longo dos tempos e dos espaços" (p. 17). Pode-se dizer, a partir de seus argumentos, que a atualização sistemática do primeiro contato constitui um processo performativo, que produz e modifica, a cada vez, o que Clarisse denomina os "sentidos do contato" (pp. 23-30), isto é, tanto as construções de significação quanto as formas e transformações da experiência sensível que o circundam e o atravessam. Com a apresentação, junto ao texto, de inúmeras imagens em preto e branco (às quais faltam, contudo, informações sobre as imagens originais, particularmente se são em preto e branco ou coloridas), a edição do livro permite entrever a complexidade de qualquer tentativa de compreender os sentidos do contato que o cinema registra e reconstrói, por meio da reprodução de quadros e capturas de tela de algumas das obras comentadas e analisadas.

Se o estudo do que Clarisse denomina filmes de contato depende de uma compreensão histórica do que está em jogo em cada uma das obras abordadas, sua análise de Os últimos isolados (Adrian Cowell, 1967-1999), Corumbiara (Vincent Carelli, 1986-2009) e Os Arara (Andrea Tonacci, 1980-) busca pensar a relação entre culturas como experiência aberta à ressignificação e à reconstrução sensível. Em termos metodológicos, a compreensão histórica do contato, em cada obra, implica a contextualização de cada caso e sua reconstituição no tempo distendido do processo histórico, enquanto a interrogação do contato como experiência aberta permite reconhecer a densidade singular de cada situação de contato e explorar relações entre contextos muito diferentes entre si, com base no reconhecimento do pertencimento das três obras a uma mesma condição de engajamento "num desafio em comum: filmar - ao longo de um extenso período - situações de primeiro contato com índios isolados" (p. 18). 
A essa dupla articulação teórico-metodológica corresponde a consideração articulada, nas análises dos filmes, de "duas instâncias relativas à temporalidade" (p. 19): a compreensão histórica do contato conduz aos movimentos extensos que as próprias obras reconstituem e que as condicionam de modos distintos; já a experiência aberta do contato emerge sob a forma de momentos intensos que as obras assimilam, que as transformam por dentro.

Para compreender os momentos intensos da cena do contato, em sua relação com os movimentos extensos da história, Clarisse recorre, no primeiro capítulo do livro, intitulado "Filmar o contato", a um diálogo com algumas tentativas antropológicas de compreender narrativas indígenas sobre o tema e o modo como figuram o contato, recorrentemente, por meio do recurso "a qualidades da experiência sensível" (p. 30). Ao mesmo tempo, a autora considera "várias definições que as sociedades ameríndias têm de imagem" (p. 70), buscando reconhecer a agência indígena nas imagens e nos filmes de contato, mesmo diante da situação de "desconhecimento por parte do sujeito filmado em relação ao que significa ser filmado, tal como nos filmes dos primeiros tempos" (p. 66). Clarisse aborda o "jogo intrincado em que estão em relação tanto os modos de ver e as formas de aproximação ocidentais quanto os modos de ver e as formas de aproximação ameríndias" (p. 70), para que seja possível reconhecer a emergência histórica da agência do "mundo ameríndio" (p. 20) e o deslocamento mútuo das configurações culturais ocidentais e indígenas que está implicado no contato, tal como se insinua e se desdobra nos contextos diversos abordados pelos cineastas, a quem serão dedicados capítulos específicos: Cowell é o tema do terceiro; Vincent, o do quarto; Tonacci, o do quinto.

A situação de contato constitui uma ocasião de equívocos de parte a parte: "No caso dos filmes de contato aqui em questão, o equívoco, ao ser explicitado, torna visível a relação entre diferentes perspectivas - os mundos, em certo sentido - incomensuráveis que se convocam em determinada cena" (p. 56). Assim, se "a cena do contato é equívoca" (p. 185), é porque nela se articulam um regime do visível, associado ao desejo de mostrar que orienta a realização de todo filme e ao privilégio ocidental do sentido da visão, e um regime do tato e da escuta, associado ao reconhecimento de um lugar próprio do invisível e à possibilidade de elaboração do equívoco entre mundos no nível do corpo, a partir de uma "desierarquização dos sentidos" (p. 70) e por meio de "uma mise-en-scène tateante, conduzida pelos corpos e pela relação tátil e sonora que experimentam" (p. 70).

A equivocidade da cena do contato resguarda uma produtividade crucial, que exige elaboração e permanece aberta: a produtividade de mundos diferen- 
tes, na qual se pode reconhecer uma potência cosmopoética, em vez de pontos de vista distintos sobre um mundo comum supostamente dado. Penso que a introdução dos conceitos de cosmopoética e cosmopolítica numa leitura do livro de Clarisse pode amplificar alguns dos temas de sua argumentação de modo produtivo, permitindo pensar o problema do mundo comum como construção, e não como dado. Se o conceito de cosmopoética se refere à produção de mundos radicalmente diferentes (cuja relação entre si articula intraduzibilidade e opacidade), é preciso reconhecer que toda cosmopoética se encontra inscrita em encadeamentos de cosmopolíticas - isto é, acoplamentos relativos a formas de configuração e partilha do mundo comum (que pode emergir por meio do diálogo intercultural e da tradução).

Gostaria de sugerir que a potência cosmopoética que a cena do contato mobiliza é o que torna possível pensar a intraduzibilidade da relação entre mundos diferentes como um problema cosmopolítico, isto é, de construção de um mundo comum ainda não existente, uma vez que a diferença entre mundos não encontra solução em nenhuma "tradução assertiva" (p. 54), "sendo a tradução entre os mundos realizada sem apaziguamento" (p. 71). Enquanto a potência cosmopoética inventa mundos diferentes e irredutíveis, na medida de sua intraduzibilidade, isto é, da impossibilidade de traduções assertivas e apaziguadas de seus termos, a tarefa da tradução permanece crucial, pois é por meio dela e de seu inacabamento constitutivo que o mundo comum inexistente pode vir a ser construído, projetado e imaginado.

Interrogar como o contato foi filmado é interrogar o cinema como aparelho de produção de formas sensíveis e de significação que circunscrevem e inscrevem a relação entre culturas, ao mesmo tempo em que se pode entrever, igualmente, nesse percurso, a questão do cinema como aparelho cosmopoético (Ribeiro, no prelo). Uma vez que nenhum aparelho é neutro e dissociado da história, nem a história dissociada dos aparelhos que a (con)figuram, pensar a relação entre culturas que o cinema registra e reconstrói é, também, questionar o enquadramento cultural que constitui o aparelho cinematográfico, em sua emergência histórica associada ao colonialismo, em geral, e ao colonialismo interno da chamada "sociedade nacional" brasileira em relação aos povos indígenas, em particular. Dessa forma, o que emerge na cena do contato, tal como esta se inscreve nos filmes estudados por Clarisse, são possibilidades de "reinvenção do cinema" (p. 35), diante das quais é preciso perguntar: "como o cinema documentário é alterado ao mesmo tempo em que altera a experiência do contato interétnico?" (p. 30). Para responder a esta pergunta, Clarisse articula uma perspectiva antropológica e cosmológica e uma compreensão histórica da relação entre culturas - e aqui se demarca um itinerário duplo, entre 
o campo circunscrito do indigenismo (e do cinema indigenista) e a tradição em transformação do documentário (e do filme etnográfico).

A questão do contato é uma das preocupações centrais do indigenismo, entendido por Clarisse como "todo o tipo de ação, iniciativa ou prática engajada em prol dos direitos indígenas, partam elas da sociedade civil, do Estado ou dos movimentos sociais" (p. 35). Desde o final da década de 1970, em particular, acentua-se a relevância da "questão da aparência do índio, ou seja, de sua imagem" (p. 36), num contexto de articulação entre a reivindicação de direitos, a começar pelos direitos territoriais, e a questão da visibilidade indígena - ignorada ou negada pelo Estado, que projeta e executa a construção da Transamazônica, exemplo paradigmático da violência catastrófica do desenvolvimentismo; manipulada e falsificada por fazendeiros e outros atores sociais interessados em tomar para si as terras indígenas (p. 191); desejada pela televisão, em sua posição ambivalente nesse processo, como parte de uma "lógica midiática" (p. 237) que "queria exatamente, agora a todo custo, expor as imagens dos índios" (p. 236).

Ao reconhecer a relação entre imagem, política e direito, a argumentação de Clarisse pode se voltar para o arquivo de imagens de diferentes mídias que registra, parcialmente, a história do contato e das sociedades indígenas que vivem no território brasileiro. Nesse contexto, a autora apresenta uma instigante leitura a contrapelo de algumas das imagens produzidas pelo Major Luiz Thomaz Reis, no âmbito da Comissão Rondon e do horizonte integracionista que define a política indigenista do Estado brasileiro, no período de atuação do Serviço de Proteção aos Índios (SPI), entre 1910 e 1967. Em Ao redor do Brasil (Major Thomaz Reis, 1932), Clarisse observa "a presença e participação dos indígenas em cena" (p. 42) e reconhece um transbordamento do "programa de Estado" (p. 44) em gestos de devolução do olhar à câmera, em vislumbres do cotidiano e de suas partilhas na situação de contato, em disjunções das tentativas de "integração" dos "selvagens".

Se os filmes estudados podem ser compreendidos como parte do cinema indigenista que se inaugura com a obra do Major Thomaz Reis, no SPI, e se prolonga no período que sucede a criação da Fundação Nacional do Índio (FUNAI), no final de 1967, suas relações com a política indigenista praticada pelo Estado, pela sociedade civil e por movimentos sociais são heterogêneas, assim como seus efeitos na esfera da "política indígena", "protagonizada pelos próprios indígenas e que não se reduz ao "indigenismo"” (p. 35). Nesse contexto histórico, a política indigenista do Estado é assumida pela FUNAI, ao mesmo tempo em que se consolidam organizações de indigenismo da socie- 
dade civil e dos movimentos sociais, como a Associação Nacional de Ação Indigenista (Anaí) e o Centro de Trabalho Indigenista (CTI), entre outras.

Cada cineasta estudado ocupa uma posição distinta no campo político e no campo cinematográfico e audiovisual do indigenismo - assim como nos campos da política indígena e do emergente cinema indígena ${ }^{1}$. Cowell realiza seu trabalho como um ator social transnacional, e sua trajetória decorre de sua atuação na televisão britânica (BBC) e o conduz ainda a contextos distantes do brasileiro, como a Birmânia e o Tibet (pp. 117-118). A trajetória de Vincent articula seu envolvimento pessoal com povos indígenas de diferentes contextos e um interesse apenas posterior nas possibilidades do vídeo e do cinema, a partir de uma experiência com a fotografia no Centro Ecumênico de Documentação e Informação (CEDI) que inaugura um procedimento consolidado, definitivamente, com o projeto Vídeo nas Aldeias: a prática de devolver as imagens aos índios (pp. 175-177). Ao mesmo tempo, o projeto fundado por Vincent na década de 1980 é indissociável da emergência do cinema indígena no Brasil contemporâneo. Tonacci, por sua vez, emerge como cineasta na década de 1960, quando trabalha com Rogério Sganzerla e inicia sua trajetória autoral, e "mantém uma série de encontros com diferentes grupos indígenas e indigenistas, não apenas no Brasil, mas também no Arizona e no Novo México (EUA, 1979-1980)" (p. 225), tendo sido parte da inspiração que conduziu à fundação do próprio Vídeo nas Aldeias.

O gesto analítico que sustenta a leitura a contrapelo das imagens do contato filmadas pelo Major Thomaz Reis depende da articulação de uma perspectiva histórica que reconhece nos anacronismos (como tem argumentado, por exemplo, Georges Didi-Huberman [2015] em relação à história da arte) uma pulsação crucial da pesquisa, articulando uma compreensão do processo histórico e da experiência que a ele está associada. Quando argumenta que, "[p]ara além da intenção do Estado [nas imagens da Comissão Rondon], há aquilo que, a despeito do que se pretende mostrar, acaba se tornando visível posteriormente, a partir da retomada futura do filme por seus espectadores" (p. 47), Clarisse parte de uma crítica às análises de Fernando de Tacca (2001) sobre a eficiência da "imagética da Comissão Rondon" (ou de uma extrapolação dos argumentos do autor, em todo caso) e reivindica a necessidade de uma reescrita da história das imagens do contato que reconheça, "em perspectiva reversa, modos de resistência ao olhar e ao impulso integrador" (p. 50), assim como os indícios do "futuro catastrófico do projeto nacional de desenvolvimento" (p. 49). Se a re-

1. A distinção entre política indigenista e política indígena pode conduzir à suposição de uma distinção análoga entre cinema indigenista e cinema indígena, mas não se deve supor um paralelismo previamente estabelecido entre os campos da política e do cinema. Será preciso pensar de modo disjuntivo as eventuais correspondências e os desajustes e afastamentos entre cada um dos termos em questão. 
tomada das imagens por espectadores e espectadoras de outros tempos permite ver o que não se pretendia tornar visível no passado, é porque o anacronismo do processo histórico e de sua experiência está inscrito não apenas no gesto analítico de Clarisse, mas na própria condição das imagens, em geral, e dos filmes de contato, em particular. Dessa forma, ao procurar "acompanhar os filmes em sua imanência", a autora propõe "um gesto analítico também processual" (p. 20), no qual é possível encontrar algumas de suas contribuições mais interessantes para os estudos de cinema, entre outros campos do saber com os quais sua pesquisa dialoga.

O conceito de processo constitui uma categoria central da pesquisa de Clarisse, que recorre à "noção de cinema-processo, tal como formulada por Cláudia Mesquita" (p. 20) para pensar os movimentos extensos das narrativas fílmicas. Enquanto a cena do contato emerge como momento intenso que implica o desregramento dos filmes a partir do deslocamento equívoco que caracteriza a experiência das filmagens, os movimentos extensos da história aparecem em sua relação com a montagem e com as formas de organização do tempo que a definem. A extensão temporal e o reconhecimento da processualidade constitutiva dos filmes aparecem, no livro, no que poderia parecer um detalhe: a escolha de datação das obras cinematográficas e audiovisuais citadas, por meio da delimitação de seus períodos estendidos de realização, em vez da mera indicação de anos isolados de lançamento do produto final. Nesse contexto, é ainda mais notável a datação em aberto de Os Arara, de Andrea Tonacci: "1980-". O "inacabamento da história" a que se refere o título do livro corresponde à incompletude aberta da série de Tonacci, que se inscreve graficamente no hífen sem complemento.

A extensão temporal dos períodos de realização dos filmes constitui apenas um dos aspectos mais objetivos de sua dimensão processual, que envolve ainda as alterações nas vidas dos sujeitos envolvidos nas filmagens e a configuração de "situações heterogêneas, filmadas de maneiras diferentes, com equipamentos diversos, algumas vezes inclusive por equipes distintas" (p. 76), entre as quais se estabelecem "muitas lacunas temporais" (p. 76). De fato, no segundo capítulo do livro, intitulado "Narrar o contato", trata-se de pensar o cinema-processo, definindo os filmes de contato como "filmes-processo", "em função de sua interseção com o vivido" (p. 78) e do "fato de sua forma ser indissociável de seu processo de realização" (p. 78). Clarisse identifica "alguns dos procedimentos narrativos que os filmes-processo dispõem para narrar suas experiências: 1) Modos da reencenação; 2) Atos de fala; e 3) A retomada das imagens" (p. 79), buscando pensar suas relações com alguns marcos históricos da tradição em transformação do documentário (e do filme etnográfico). 
Nesse contexto, os exemplos discutidos delimitam um corpus em que a abordagem das questões do contato e da relação entre culturas é indissociável da processualidade aberta que Clarisse inscreve, mais uma vez, na própria datação das obras. Alguns dos exemplos mais significativos são: "Nanook, o esquimó (1910-1922)" (p. 81); “A caça ao leão com arco (1958-1965)” (p. 86); "Jaguar (1954-1967)" (p. 87), "Cabra marcado para morrer (1964-1984)". Com base no reconhecimento da processualidade como dimensão constitutiva do documentário e do filme etnográfico, inscrita na datação ampliada dos filmes e confirmada em comentários analíticos interessados nos traços de heterogeneidade e de múltiplos tempos que cada obra abriga, Clarisse consolida um pano de fundo crucial para sua análise das imagens de Cowell, Vincent e Tonacci, em suas relações com procedimentos fundamentais da história do documentário, seja por seu caráter referencial, seja pelo que seria preciso começar a reconhecer, efetivamente, como sua potência cosmopoética, se assim posso sugerir.

Em Robert Flaherty, encontramos um caso inaugural, ainda que limitado em seus efeitos, do procedimento de restituição e de devolução das imagens aos sujeitos filmados. Em Nanook, o feedback torna possível colher impressões sobre o filme, configurando a "invenção de um método" (p. 83), mas "o processo do filme (filmar, montar, restituir a imagem aos sujeitos filmados, voltar a filmar)" (p. 83) não é incorporado deliberadamente à sua forma, que está baseada numa reconstituição da realidade histórica em que "tudo é assumido como "realidade presente"” (p. 84). Diferentemente da reconstituição, a reencenação operará, em outros filmes, com um uso diferente do feedback: "os sujeitos filmados são mostrados na narrativa como espectadores do próprio filme ou de outras imagens" (p. 84), engajados num processo de elaboração do passado no presente, e não de reconstituição do passado. A reencenação explicita a potência cosmopoética da restituição das imagens aos sujeitos filmados (cujas possibilidades permanecem denegadas na reconstituição, embora parcialmente visíveis e perceptíveis).

Com Jean Rouch e sua "antropologia compartilhada", que é comparável a propostas contemporâneas de "antropologia reversa ou simétrica" (p. 90), são os atos de fala e os comentários sobre as imagens filmadas que revelam sua potência cosmopoética, na medida em que, quando o cineasta francês propõe "a inclusão do comentário improvisado em voz over, seja pelos nativos, seja por ele próprio" (p. 87), "o que se pretende é sonorizar o filme a partir de uma camada de sons que acrescenta sentido àquilo que vemos na imagem, sem necessariamente reafirmar o que se vê, mas sim intervindo sobre a cena, modificando-a" (p. 87-88). Em Eu, um negro, por exemplo, o feedback produz 
um suplemento de sentido, uma espécie de excesso que se acrescenta à falta de som direto nas filmagens. Na medida em que "os comentários produzidos durante o feedback são incorporados à matéria fílmica" (p. 89), o cinema se transforma a partir do contato com a potência cosmopoética da relação de alteridade, permitindo "que o cineasta saia de si, deixe sua condição de colonizador ou de pesquisador, e entre em transe, no interior de uma outra cultura" (p. 91).

O cinema de Pierre Perrault aparece também como outro exemplo de cinema-processo e de exploração da potência cosmopoética do aparelho cinematográfico; nesse caso, em Para que o mundo prossiga, por exemplo, "a mediação por meio do uso da câmera e do microfone ganha primazia" (p. 92), num processo de produção da memória coletiva. Se o interesse de Perrault "pela oralidade, pelos atos de fala das pessoas ordinárias com quem se encontra, a quem escuta e filma" (p. 92), é indissociável de um recurso à fabulação das personagens, o cinema de Eduardo Coutinho exemplifica, por sua vez, a dimensão de fabulação que está contida na retomada das imagens, que permite ao cinema pensar a história e, ao mesmo tempo, abrigar "caminhos que poderiam 'ter sido' trilhados e que ainda se mantêm como possibilidade e abertura no presente" (p. 102). Em Cabra marcado para morrer, por exemplo, "a linearidade e a construção progressiva da história" (p. 103) são questionadas a partir de uma reivindicação do que poderia ter sido, cuja importância política pode ser associada à potência cosmopoética do gesto de retomada das imagens que restam e, ao mesmo tempo, das imagens que faltam.

Se o corpus comentado por Clarisse no segundo capítulo do livro define um pano de fundo para sua análise, por meio de uma genealogia ou arqueologia de procedimentos de compartilhamento da mise-en-scène documentária característicos do cinema-processo, a questão do contato se destaca, sobre esse pano de fundo, por sua intensidade radical e por sua abertura irredutível: a relação compartilhada na cena do contato corresponderia, assim, "ao ponto extremo - ao grau zero - da mise-en-scène documentária" (p. 103). Os filmes de contato estudados por Clarisse aspiram a "um deslocamento da relação colonizadora nas filmagens, tornando-a objeto de reflexão na montagem" (p. 105), por meio da construção de "contranarrações" (p. 103), conforme uma busca de complexificação e de problematização da experiência do contato que a autora comenta, igualmente, em relação à "trilogia sobre o primeiro contato, tal como ocorrido nos vales das Terras Altas de Papua-Nova Guiné, realizada por Bob Connolly e Robin Anderson" (pp. 107-113).

No terceiro capítulo do livro, intitulado "Os últimos isolados: testemunhar contra o Estado", Clarisse argumenta que Adrian Cowell busca historicizar os 
momentos intensos do contato intercultural, recorrendo a narrações de contextualização geral, a testemunhos registrados em depoimentos, a recriações e a reencenações de situações, ao reenquadramento e à remontagem de registros iconográficos e fotográficos do contato e da colonização, para reconstituir a cena do contato e inscrevê-la no processo histórico mais abrangente de que ela faz parte. A constante retomada e reelaboração de temas e imagens, característica da obra de Cowell, corresponde a um esforço de construção de legibilidade e a "uma concepção prioritariamente histórica do contato" (p. 122). Cowell prefere inscrever os momentos intensos do contato, tal como se pode vislumbrá-los, indiretamente, em testemunhos e reencenações, nos movimentos extensos de um processo histórico que percorre mais de 30 anos, entre 1967 e 1999 (com filmagens de 1967 a 1998 e a montagem do material de 1996 a 1999), no qual se pode verificar um conjunto de traços comuns aos diferentes contextos que os episódios da série abordam: o dos Panará, em Fugindo da extinção; o dos Uru-Eu-Wau-Wau, em O destino dos Uru-Eu-Wau-Wau; e o dos Avá Canoeiro, em Fragmentos de um povo.

Assim, se Cowell propõe um tratamento alusivo, ilustrativo e paradigmático do contato (p. 121), que aparece em cenas ou sequências curtas, nas quais a câmera se posiciona atrás dos brancos e permanece intocada e, portanto, alheia ao que Clarisse descreve como um "regime do tato" (pp. 50-59), no qual "a câmera tem existência material (possui agência), [...] parece tocar os corpos dos sujeitos filmados assim como é tocada por eles" (p. 57), é porque a perspectiva de Cowell enseja um movimento de aproximação gradual em relação aos índios, no processo das filmagens, e uma revelação genealógica do "contato como processo histórico" (p. 126) que remonta à chegada dos colonizadores europeus, no passado mais distante. De fato, para Cowell, nessa história, o contato, "mesmo quando se almeja 'pacificador', não evita a catástrofe que o sucede" (p. 134). A consciência da catástrofe conduz a perspectiva "historicizante" (p. 122) de Cowell a uma posição crítica em relação ao Estado, que aparece como seu "inimigo' preferencial” (p. 123), e a uma busca de prestar testemunho, que passa por um trabalho de "desidentificação" do cinema em relação à cultura em que surge (p. 159), na qual os índios permanecem excluídos da cena política.

Uma vez que a visibilidade é um valor característico da genealogia ocidental, moderna e colonial do cinema, e parte da resistência indígena opera por meio da reivindicação da invisibilidade, o cinema de Cowell deve suplementar (como devem fazer, em geral, os filmes de contato) uma falta de imagens, criada tanto pela violência do processo histórico quanto pelas estratégias indígenas de invisibilidade, para que seja possível "colocar os índios em cena frente 
às políticas públicas, e não exatamente diante do cineasta, diante da câmera" (p. 171). Cowell confronta o inimaginável da experiência do contato por meio da remontagem de imagens, "a partir de um trabalho histórico e iconográfico" (p. 157), de um lado, e por meio de "uma estratégia paradoxal de filmar o invisível (constatar sua existência) sem, contudo, torná-lo visível” (p. 163), de outro, numa busca que ultrapassa o quadro institucional do Estado, não sendo mais acompanhada pela FUNAI, e se inscreve numa recorrente "estratégia de zoom in nas montanhas", em busca da presença indígena que permanece no extracampo.

No quarto capítulo do livro, "Corumbiara: resistir ao enquadramento", Clarisse reconhece que a busca de evidências sensíveis do que permanece invisível - e do inimaginável: o genocídio - constitui o ponto de partida do filme de Vincent, cujo processo envolve o registro dos momentos intensos do contato com o objetivo mais imediato de provar a existência de índios que sobreviveram a um massacre, na gleba de Corumbiara. Há, assim, um sentido performativo nas imagens das cenas do contato que Vincent filma, acompanhando o trabalho de Marcelo Santos, da FUNAI: seu propósito, no momento das filmagens, não é a realização de um filme, mas a reunião de provas da existência dos índios. Na busca de provas, a potência cosmopoética das imagens registradas por Vincent permanece encadeada, de modo teleológico, a seus usos instrumentais na luta jurídico-política pelos direitos indígenas.

O processo de elaboração do filme corresponde a um movimento retrospectivo sobre o contato e a ação de curto prazo a que as filmagens estavam associadas, conduzindo a uma mudança de propósito na qual a potência cosmopoética irá transbordar a teleologia jurídico-política da prova: Vincent "deixa a função de investigador, de pesquisador, para tornar-se, em alguma medida, narrador" (p. 181). A montagem de Corumbiara identifica cronologicamente as imagens filmadas, enquanto a narração de Vincent oferece "um testemunho em primeira pessoa" (p. 180), conforme uma escolha que é tanto estilística quanto ética, marcada pelo reconhecimento de "certa insuficiência das imagens, incapazes de mostrar mais do que [...] corpos, gestos e falas inapreensíveis para os indigenistas e para o espectador" (p. 191). A passagem da insuficiência das imagens, característica de seu contexto inicial de filmagem, para sua retomada e sua remontagem articula a questão da (in)visibilidade - as imagens tornam visíveis os índios, mas os sentidos dessa visibilidade permanecem disputados, imprecisos, indecidíveis - e a questão da (in)traduzibilidade - a passagem dos Kanoê do extracampo para o campo, quando se realiza o contato, corresponde a uma passagem "da incompreensão daquelas vozes à sua tradução pelas le- 
gendas" (p. 193) e aparece como uma "transformação 'protopolítica' da voz em palavra, em instância narradora do próprio filme" (p. 193).

Figurando os indígenas entre (in)visibilidade e (in)traduzibilidade, Corumbiara permite a Clarisse reconhecer, em sua análise, o paradoxo do compromisso do indigenismo político e cinematográfico, em geral, com um regime do visível, com uma demanda de visibilidade, em suma, com uma visualidade e com as violências que a sustentam. Esse paradoxo se evidencia no encontro com o "índio do buraco", que aprofunda a fenomenologia tensa da cena do contato, conduzindo-a a um extremo de intensidade, seja por inserir Vincent "em risco real na situação da tomada" (p. 203), diante do índio que ameaça atacá-lo com flechadas, seja por instaurar "uma espécie de crise quando, em retrospecto, na montagem, Vincent reflete sobre o acontecimento" (p. 203). Por sua recusa a se deixar filmar pela câmera de Vincent, o "índio do buraco" aparece como uma figura da persistência do "extracampo como lugar de resistência à visualidade" (p. 203) imposta pelo filme e pelas instituições.

Se a potência cosmopoética do contato com a opacidade resistente do "índio do buraco" se desdobra, em Corumbiara, numa interrogação reflexiva do olhar branco que busca enquadrá-lo e das "diferentes dimensões temporais" (p. 206) que se articulam no processo do filme, a última parte do quarto capítulo do livro de Clarisse se dedica a insinuar um dos desdobramentos mais importantes de sua pesquisa sobre as imagens do contato: o estudo dos modos de ver e das experiências audiovisuais decorrentes da emergência atual do cinema indígena. A devolução do olhar em direção aos brancos é o gesto fundamental que se desdobra no filme Desterro Guarani (2011), de Ariel Ortega, Patrícia Ferreira, Ernesto de Carvalho e Vincent Carelli. A autoria compartilhada entre indígenas (Ariel e Patrícia) e não indígenas (Ernesto e Vincent) posiciona o filme na passagem - ou na "ponte clandestina", para utilizar e deslocar, ao mesmo tempo, uma imagem poética que José Carlos Avellar (1995) reivindica para pensar o cinema latino-americano - entre cinema indigenista e cinema indígena.

É como ponte cosmopoética e cosmopolítica que o cinema emerge do contato, sempre que suas imagens e sons se abrem para a experiência incomensurável do encontro equívoco entre culturas, e é com Andrea Tonacci que será possível completar o quadro incipiente dessa ponte em construção, que é também uma ruína à qual será preciso retornar e cuja forma frágil será preciso sustentar. Como Clarisse argumenta no quinto capítulo do livro, "Os Arara: sustentar o inacabamento", quando Tonacci filma o contato, há uma abertura da cena para a possibilidade de trânsito entre os lados da câmera. Essa abertura de uma ponte no interior da cena do contato corresponde, na elaboração 
do movimento extenso da narrativa fílmica, a uma abertura da história e um questionamento da narratividade ocidental.

Em sua primeira experiência indigenista, com os Canela Apanyekrá do Maranhão, em 1977, Tonacci adota o que Clarisse denomina uma "câmera participante" (p. 228, p. 235), que atua em relação aos corpos envolvidos na situação de contato e em seus equívocos. Há uma "relação estreita do filme com a temporalidade própria dos Canela" (p. 233), que, ao mesmo tempo em que evidencia uma tentativa de assimilação da temporalidade indígena, "nos mantém alienados em relação ao que vemos, nos mantém como visitantes, observadores fora da cena" (p. 235). A compreensão das obras indigenistas de Tonacci sobre o pano de fundo de sua trajetória como cineasta permite entrever lugares comuns entre Olho por olho (1965) e Bang Bang (1970), de um lado, e Conversas no Maranhão (1977-1983) e Serras da Desordem (2006), além de Os Arara: um interesse no deslocamento (e a figura do carro como dispositivo de experimentação audiovisual e narrativa); a busca de "desestruturar a narrativa e sua finalidade" (p. 224); a articulação entre "dimensão processual" e "caráter relacional" (p. 224) da realização cinematográfica.

Em sua experiência com os Arara, que se inicia em 1980, Tonacci trabalha em contrato com a TV Bandeirantes, com previsão de três episódios de 60 minutos (p. 236). Apesar de trabalhar em contrato com um canal de televisão, Tonacci escapa duplamente à "lógica midiática" (p. 237): por um lado, ao assumir um interesse num tempo mais longo de produção; por outro, ao manter os índios no extracampo durante os dois primeiros episódios, não para excluílos da cena do contato, sobre a qual eles exercem "forte tensão" (p. 237), mas para poder registrar a experiência do contato em sua duração dilatada e incerta. Ali onde o Estado apaga os indígenas e a televisão os expõe apressadamente, Tonacci opera um movimento de abertura radical à alteridade. $\mathrm{O}$ recuo em relação ao imediatismo das demandas televisivas o conduz a realizar, no primeiro episódio da série, uma "contextualização histórica da Terra Indígena Arara, feita a partir de cenas que explicitam a interação com relatórios institucionais, matérias de jornal, fotografias e mapas" (p. 240), com "uso sistemático do material de arquivo [...] empregado para mostrar o contexto que antecede o presente das filmagens" (p. 240). Os índios permanecem no extracampo, e o contato é objeto de uma espera produtiva, permeada pela troca de presentes e pela proximidade física das equipes do filme e da FUNAI, diante do "risco de um ataque indígena associado às restrições espaciais e perceptivas que a floresta estabelece - ali não se encontra o horizonte aberto" (p. 245). Conforme a consagrada expressão de Jean-Louis Comolli (2008), o "risco do real" tensiona a narração do filme. 
O segundo episódio aborda o ataque dos Arara ao Posto de Vigilância 1, explicitando um tensionamento da cena a partir de seus vestígios. O sentido de risco se acentua, mesmo com a ausência de registro direto da presença dos indígenas: "Do extracampo, mesmo não sendo enquadrados, os Arara participam da cena; sua presença nela incide" (p. 249). O primeiro contato será, então, efetivado no terceiro episódio de Os Arara, que permanece não montado e não foi veiculado pela TV Bandeirantes (p. 251). O movimento de aproximação dos Arara é filmado com uma oscilação entre movimentos de zoom in e de zoom out, e o contato se converte numa irrupção desregrada do regime do tato no cerne das imagens. Assim como os índios tateiam "os corpos dos brancos, cabelos, barbas, e também [...] seus artefatos: câmeras fotográficas, gravadores e a própria câmera que filma" (p. 251), "Tonacci também usa a câmera para 'tatear' os corpos dos indígenas" (p. 251), em suas relações com seu corpo e com os corpos das pessoas das equipes do filme e da FUNAI. "São os corpos que dirigem a cena e não mais apenas o olhar, o que desregra a mise-en-scène do filme. A partir do atrito que surge entre corpos e câmera emerge o que há de intocável" (p. 253).

Uma das dimensões mais importantes do regime do tato em Os Arara está relacionada ao sentido reflexivo da inscrição do corpo de Tonacci diante da câmera. "Usando a movimentação de seu próprio corpo e a relação de seu corpo com a câmera e o microfone, o cineasta explicita a operação cinematográfica: como se constitui a cena" (p. 257). O regime do tato desencadeia, assim, a abertura da "passagem entre mundos [...], ainda que o equívoco permaneça como elemento fundante" (p. 256). Se o regime do visível teria permanecido baseado numa relação de enquadramento distanciado, a presença dos indígenas no extracampo pertence um processo de perturbação do visível a partir do invisível, que se desdobra, em seguida, na cena do contato, em um regime do tato e da escuta, no qual o compartilhamento do quadro e a coabitação da cena (p. 258) e a "experiência de reversibilidade do contato" (p. 265) fazem emergir indícios do comum, de um "contrato" com os índios que é suplementar ao contrato com a televisão, sua narrativa e sua visualidade dominante, em suma, de uma comunidade por vir, que permanece inacabada, assim como a série de Tonacci.

O inacabamento da série é uma inscrição formal da comunidade por vir, que emerge provisoriamente da "reciprocidade entre os envolvidos na situação de filmagem" (p. 261). Clarisse escreve: "A opção do cineasta de não montar o material está relacionada não apenas à quebra de contrato com a TV Bandeirantes, mas também à natureza do 'contrato' que o filme acabou por fazer com os Arara e que envolve fortemente a sociabilidade deles" (p. 262). Ao or- 
ganizar numa narrativa os movimentos extensos que conduziram ao momento intenso do contato, Os Arara assume a forma de um tríptico: "se trata de uma série composta por três episódios contíguos, coextensos, entretanto heterogêneos" (p. 263). Cada episódio se abre para o outro, configurando uma estrutura em aberto, que recusa ativamente a narratividade ocidental, associada ao desfecho e ao fechamento, à teleologia e à forma acabada. A recusa da narratividade ocidental constitui um prisma para que Clarisse apresente uma leitura de Serras da desordem como um filme-processo, marcado pela "impossibilidade de traduzir a experiência de Carapiru" (p. 269) e pelo reconhecimento de uma equivalência na incomunicabilidade, de uma aproximação na intraduzibilidade, que define as relações entre Tonacci (e o cinegrafista Aloysio Raulino, que também aparece em cena) e Carapiru, na medida em que, mesmo sem que exista uma comunidade pré-definida que os abrigue, "eles estão juntos vivenciando a experiência do filme, eles estão em cena, compartilhando as histórias de suas errâncias e dando continuidade a elas, dando prosseguimento ao mundo, em movimento" (p. 271).

Como reconhecida e premiada contribuição aos estudos de cinema e ao campo interdisciplinar da comunicação, além de outras disciplinas, como a história e a antropologia, o livro de Clarisse indica uma série de possibilidades temáticas e analíticas que seria interessante desdobrar: o estudo do cinema indigenista e do cinema indígena; a reescrita a contrapelo da história do contato, buscando reconhecer as resistências indígenas ao genocídio que se projeta sobre suas formas de vida; o estudo de outros contextos históricos em que se produziram imagens de contato e se articularam suas cosmopolíticas e cosmopoéticas; a pesquisa sobre o cinema-processo e suas derivações possíveis nos campos expandidos do audiovisual e da arte etc. Não é preciso supor que os equívocos relacionados ao contato como processo histórico e como experiência devem conduzir, necessariamente, à impossibilidade de um mundo comum. Se, de fato, não há um mundo comum previamente dado, em relação ao qual as diferenças em jogo na situação de contato seriam meramente variações de ponto de vista, a construção de um mundo comum, em meio à intraduzibilidade, à opacidade, à incomunicabilidade, constitui uma das tarefas políticas fundamentais de nossos tempos. Dar prosseguimento ao mundo, em movimento, é uma das formas de articular as cosmopoéticas disjuntivas da cena do contato e as cosmopolíticas que insinuam a possibilidade de construir um mundo comum, apesar de tudo. 


\section{Referências bibliográficas}

Avellar, J. C. (1995). A ponte clandestina: Birri, Glauber, Solanas, García Espinosa, Sanjinés, Alea: teorias de cinema na América Latina. São Paulo; Rio de Janeiro: Edusp; Editora 34.

Comolli, J.-L. (2008). Ver e poder - A inocência perdida: cinema, televisão, fiç̧ão, documentário. (C. Guimarães \& R. Caixeta, Orgs., A. de Tugny, O. Teixeira \& R. Caixeta, Trads.). Belo Horizonte: Editora UFMG.

Didi-Huberman, G. (2015). Diante do tempo - História da arte e anacronismo das imagens. (V. Casa Nova e M. Arbex, Trads.). Belo Horizonte: Editora UFMG.

Ribeiro, M. R. S. (no prelo). Do inimaginável. Goiânia: Editora da UFG.

Tacca, F.de. (2001). A imagética da Comissão Rondon. Campinas, SP: Papirus. 